\title{
Docetaxel: Efficacy in First- and Second-Line Therapy of Advanced Breast Cancer
}

\author{
Wirksamkeit von Docetaxel in der First- und Second-line-Therapie des \\ fortgeschrittenen Mammakarzinoms
}

\author{
J. Crown \\ St. Vincent, Dublin, Ireland
}

D ocetaxel has been subjected to an unprecedented array of randomized clinical trials covering a variety of clinical scenarios in the last few years. The results of these trials have defined the place of the drug in the therapeutic armamentarium of advanced breast cancer rather clearly. D ocetaxel is currently considered as one of the most active single agent in that disease, even more active than adriamycin (doxorubicin) which took this place since its introduction in the mid 1970s.

\section{Treatment after Failure of Alkylating Agents}

The key study TA X 303 published in 1999 [1] compared docetaxel with doxorubicin in the second-line therapy of patients with metastatic breast cancer who had previously failed treatment ( given for metastatic disease in nearly half of them) with an alkylating agent, mostly CM F combination chemotherapy. In this international phase III study 326 patients were randomized to receive either docetaxel at a standard dose of $100 \mathrm{mg} / \mathrm{m}^{2}$ or doxorubicin given at an aggressive dose schedule of $75 \mathrm{mg} / \mathrm{m}^{2}$ every 3 weeks. There was a significant superiority of docetaxel in terms of overall response rate (48 vs. $33 \%$, $p=0,008$ ) (table 1). $7 \%$ of the patients in the docetaxel arm achieved a complete response compared with $4 \%$ in the doxorubicin arm. The difference in median time to progression ( 26 weeks with docetaxel vs. 21 weeks with doxorubicin) failed to reach statistical significance ( $p=0.0996$ in the Wilcoxon test). M edian time to treatment failure was longer with docetaxel (12 vs. 18 weeks), with a significant difference in the Wilcoxon test $(p=0.01)$ and a trend towards significance in the log-rank test $(p=0.10)$. Median overall survival was comparable (15 months in the docetaxel arm vs. 14 months in the doxorubicin arm) but there was extensive crossover. The safety profile of both drugs also showed significant advantages in favor of docetaxel. Patients treated with docetaxel had significantly fewer febrile neutropenia ( 6 vs. $12 \%$ ), severe anemia ( 4.5 vs. $16 \%$ ) or grade 4 thrombocytopenia (1 vs. $7.5 \%$ ) and needed red blood cell transfusions significantly less frequently (7 vs. $21 \%$ ). Some severe non-hematological toxicities also occurred less often in the docetaxel group, including vomiting ( 3 vs. $12 \%$ ) and stomatitis ( 5 vs. $12 \%$ ). F luid retention related to docetaxel was seldom a problem due to effective premedication with dexamethasone. O f note, no case of congestive heart failure ( $\mathrm{CHF})$, cardiac death or treatment discontinuation due to cardiac toxicity occurred in the docetaxel arm of this study while in the doxorubicin arm $16 \%$ of the patients had a severe decrease $>40 \%$ of their left ventricular ejection fraction (LVE F), 4\% developed CHF, 3 patients ( $2 \%$ ) died and 15 (9\%) had their treatment discontinued due to cardiac toxicity. In conclusion, docetaxel was substantially more active and less cardiotoxic than doxorubicin in this comparative study.

\section{Treatment after Anthracycline Failure}

In the 1970s and 80s no meaningful treatment option was available for patients who failed prior anthracycline therapy. In the last decade, however, three randomized phase III trials including a total of 851 patients were conducted which established the valuable role of docetaxel in this setting. The first study revealed a highly significant advantage of single-agent docetaxel over combination chemotherapy with mitomycin and vinblastine both in terms of response rate ( $30 \mathrm{vs.} 12 \%, p<0.0001$ ) and mediane time to progression ( 19 vs. 11 weeks, $p=0.001$ ) [2]. Moreover, treatment with docetaxel was associated with a significantly prolonged median overall survival (11.4 vs. 8.7 months; log rank $p=0.0097$, Wilcoxon $p=0.0266$ ) which is a very rare finding in the salvage setting. The survival advantage at 12-24 months is illustrated in figure 1. Similarly impressive was the superiority of docetaxel to combination chemotherapy with methotrexate and 5-fluorouracil [3], with a roughly doubled response rate ( $42 \mathrm{vs} .21 \%, p=0.0001$ ) and time to progression ( 27 vs. 13 weeks, $p<0.001$ ). There was no survival difference in this study because patients who failed methotrexate/5-fluorouracil had crossover to docetaxel treatment. Preliminary results of the third study indicated equivalent activity for docetaxel (with some suggestion for superior time to progression) compared with the FUN combination con-

\begin{tabular}{llll}
\hline KARGER & @ 2000 S. Karger G mbH , Freiburg & & $\begin{array}{l}\text { John Crown, MD } \\
\text { St. Vincent, }\end{array}$ \\
$\begin{array}{lll}\text { Fax }+497614520714 & \text { A ccessible online at: } & \text { Dublin, Ireland } \\
\text { E-mail Information@K arger.de } \\
\text { www.karger.com }\end{array}$ & www.karger.com/journals/onk & &
\end{tabular}


Tab. 1 E fficacy of docetaxel $\left(100 \mathrm{mg} / \mathrm{m}^{2}\right)$ and doxorubicin $\left(75 \mathrm{mg} / \mathrm{m}^{2}\right)$ for metastatic breast cancer after failure of alkylating therapy. R esults of a phase III study [mod. after 1]

\begin{tabular}{llllllll}
\hline \multirow{2}{*}{ g gent } & \multirow{2}{*}{$\mathrm{n}$} & \multicolumn{6}{l}{ Response, \% } \\
\cline { 3 - 7 } & & $\mathrm{CR}$ & $\mathrm{PR}$ & $\mathrm{OR}$ & $\mathrm{SD}$ & $\mathrm{PD}$ & $\mathrm{NE}$ \\
\hline Docetaxel & 161 & 7 & 41 & 48 & 34 & 12 & 6 \\
Doxorubicin & 165 & 4 & 29 & 33 & 38 & 22 & 7 \\
\hline
\end{tabular}

$\mathrm{CR}=$ Complete response, $\mathrm{PR}=$ partial response, $\mathrm{OR}=$ overall response, $\mathrm{SD}=$ stable disease, $\mathrm{PD}=$ progressive disease, $\mathrm{NE}=$ not evaluable. $p=0.008$.

sisting of vinorelbine on days 1 and 5 and 5 -fluorouracil given over 5 days as a continuous infusion via $\mathrm{H}$ ickman catheter using a portable pump device [4]. In view of the burdensome administration of the FUN regimen it can be expected that patients treated with docetaxel will experience improved quality of life in this study. Thus, it can be concluded from these randomised trials that docetaxel is an effective and well tolerated treatment option for patients with metastatic breast cancer who failed prior anthracycline therapy.

\section{Docetaxel-Doxorubicin Combination Chemotherapy}

The available treatment data provide a sound rationale for giving docetaxel and doxorubicin in combination: Both are highly active as single agents in metastatic breast cancer, and there is conclusive evidence that docetaxel is effective in patients with prior exposure and resistance to anthracyclines. Thus it appears conceivable that breast cancer cell clones surviving treatment with doxorubicin may be eradicated by simultaneous or subsequent administration of docetaxel.

The randomized phase III study TA X 306 compared combination chemotherapy with doxorubicin $50 \mathrm{mg} / \mathrm{m}^{2}$ plus docetaxel $75 \mathrm{mg} / \mathrm{m}^{2}$ (AT) with doxorubicin $60 \mathrm{mg} / \mathrm{m}^{2}$ plus cyclophosphamide $600 \mathrm{mg} / \mathrm{m}^{2}$ (AC) in the first-line therapy of metastatic breast cancer [5]. A n intent-to-treat analysis revealed a significantly higher overall response rate ( 60 vs. $47 \%, p=0.012$ ) and prolonged time to progression ( 37 vs. 32 weeks, log rank $p=0.015$ ) in the AT arm despite the lower dose intensity of doxorubicin in this regimen. $28 \%$ of the patients in the AT arm compared with $19 \%$ in the AC arm demonstrated no disease progression at 1 year. The superior activity of AT was maintained in high-risk subgroups including those with visceral disease (response rate, 59 vs. $42 \%$ ), involvement of 3 or more

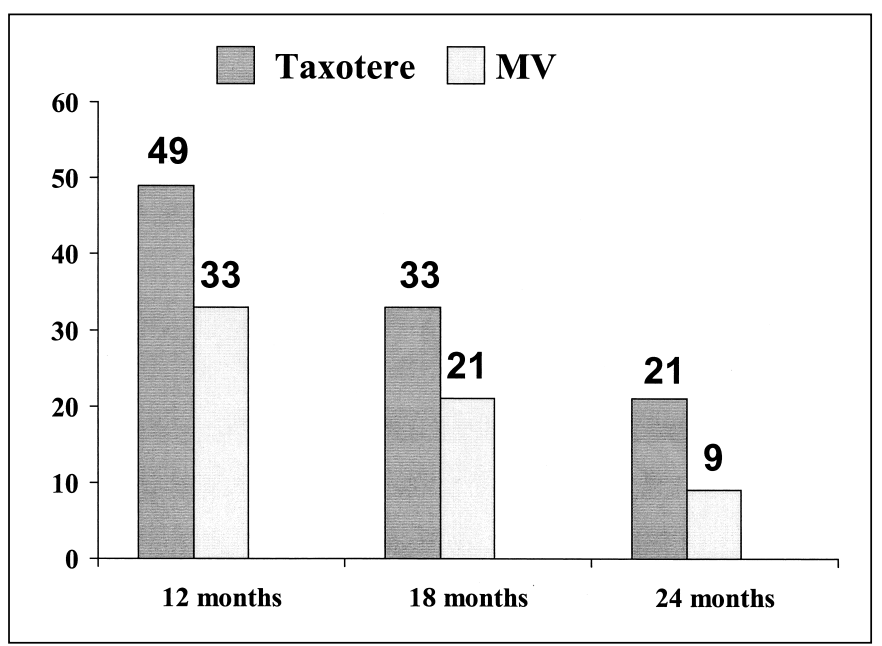

Fig. 1 Survival rates after treatment with docetaxel or mitomycin/vinblastine (MV) in patients with metastatic breast cancer who failed prior anthracycline therapy [mod. after 2].

organs ( 60 vs. $41 \%$ ) or previous adjuvant chemotherapy (54 vs. $41 \%)$. A lthough myelotoxicity was more severe with AT (neutropenia grade $3 / 4$ in $82 \mathrm{vs.} 69 \%$ of the cycles) this did not translate into an increased risk of infection ( $1 \%$ of all cycles), and the only septic death occurred in the A C arm. Non-hematological toxicity except alopecia was mild to moderate in the majority of patients in either treatment arm. Cardiac toxicity was more prominent with the $\mathrm{AC}$ regimen, possibly due to the higher cumulative dose of doxorubicin. 10 and $6 \%$ of patients evaluable for LVEF had a decrease by $\geq 20$ or $\geq 30 \%$, respectively, in the AC arm compared with 5 and $1 \%$ in the AT arm. Clinical CHF occurred in $4 \%$ (AC) and $3 \%$ of the patients (AT).

\section{Conclusions}

R andomized phase III data provided conclusive evidence that docetaxel is more active than doxorubicin in patients with metastatic breast cancer. Thus, docetaxel and doxorubicin emerge as powerful agents in the treatment of that disease. The activity of docetaxel was confirmed in patients with prior exposure and resistance to anthracyclines which provided the rationale for combining both agents. D ocetaxel/doxorubicin was the first combination regimen to show significant superiority over a standard combination in metastatic breast cancer. Studies are currently underway to establish the role of docetaxel/doxorubicin based combinations in the adjuvant setting. 


\section{References}

1 Chan S, Friedrichs $K$, N oel D, Pinter T, Van B elle $S$, Vorobiof D, D uarte R, Gil Gil M, B odrogi I, M urray $E$, Yelle L, von M inckwitz G, Korec S, Simmonds $P$, B uzzi F, G onzalez $M$ ancha $R$, R ichardson $G$, Walpole $E$, Ronzoni $M$, Murawsky $M$, A lakl M, Riva A Prospective randomized trial of docetaxel versus doxorubicin in patients with metastatic breast cancer. J Clin O ncol 1999;17:2341-2354.

2 Nabholtz J M, Senn HJ, B ezwoda WR, M elnychuk D, D eschenes $L$, D ouma J, Vandenberg TA , R apoport B, R osso R, Trillet-L enoir V, D rbal J, M olino A , N ortier J W, R ichel DJ, Nagykalnai T, Siedlecki P, Wilking N, Genot JY, H upperets PS, Pannuti F, Skarlos D, Tomiak E M, M urawsky M, A lakl M, A apro $M$, et al:
Prospective randomized trial of docetaxel versus mitomycin plus vinblastine in patients with metastatic breast cancer progressing despite previous anthracycline-containing chemotherapy. J Clin Oncol 1999; 17:1413-1424.

3 Sjöström J, B lomqvist C, M ouridsen H, Pluzanska A , Ottosson-L onn S, Bengtsson NO, O stenstad B M jaaland I, Palm-Sjovall M, Wist E, Valvere V A nderson $\mathrm{H}, \mathrm{B}$ ergh J : D ocetaxel compared with sequential methotrexate and 5 -fluorouracil in patients with advanced breast cancer after anthracycline failure: a randomized phase III study with crossover on progression by the Scandinavian Breast Group. E ur J Cancer 1999;35:1194-1201.
4 M onnier A , B onneterre J, R oche $\mathrm{H}$, Fargeot $\mathrm{P}, \mathrm{N}$ amer M, G uastalla J P, R ios M, Serin D, Culine S, Tubiana $M$, Eymard JC, A ssadourian S: Phase III study: Taxotere $^{\circledR}$ (TXT) versus 5-fluorouracil + navelbine (FU N) in patients (pts) with metastatic breast cancer (MBC) as 2nd line chemotherapy (CT) (preliminary results). A nn O ncol 1998;9(suppl 4):580 (abstr).

5 Nabholtz J M, Falkson G, Campos D, Szanto J, M artin M, Chan S, Pienkowski T, Bezwoda WR, Zaluski J, Pinter T, K rzakowski M, Vorobiof $D, L$ eonard $R, K$ ennedy I, A zli N, M urawsky M, R iva A, Pouillart P: A phase III trial comparing doxorubicin (A) and docetaxel (T) (AT) to doxorubicin and cyclophosphamide (AC) as first line chemotherapy for M BC. Proc A m Soc Clin O ncol 1999:18:485(abstr). 